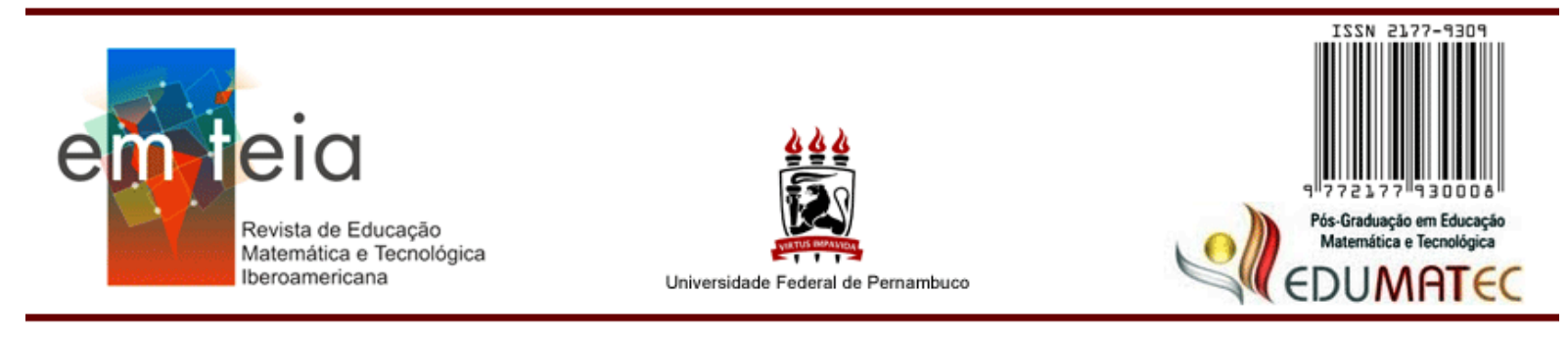

\title{
TIC NO PROCESSO DE FORMAÇÃO INICIAL DE PROFESSORES DA LICENCIATURA EM MATEMÁTICA
}

\author{
Alvaro Júnio Bertipaglia da Silva \\ Mestre em Educação - UFMT/PPGE/IE \\ UFMT - Mato Grosso - Brasil \\ alvarojuniosilva@gmail.com \\ Adelmo Carvalho da Silva \\ Doutor em Educação - UFPB/PPGE/JP \\ UFMT - Mato Grosso - Brasil \\ adelmoufmt@gmail.com
}

\section{Resumo}

Esse estudo é um recorte da pesquisa de mestrado intitulada "TIC no processo de formação inicial dos alunos do curso de Licenciatura em Matemática da UFMT". Integra as produções do Grupo de Estudos e Pesquisas em Educação Matemática (GRUEPEM) com financiamento da Capes. O objetivo foi compreender as contribuições das disciplinas de Tecnologias para o Ensino de Matemática no processo formativo dos acadêmicos do curso de Licenciatura em Matemática da Universidade Federal de Mato Grosso (UFMT), Campus Cuiabá. As investigações produzidas nessa perspectiva têm constatado que, para incluí-las de maneira eficiente, é necessário concebê-las como recurso que potencialize a aprendizagem, e não apenas como uma ferramenta para agilizar uma atividade. Neste trabalho, apresenta-se referencial teórico sobre a formação inicial de professores de Matemática para a Educação Básica, e como essa formação deve ser orientada para a inclusão das tecnologias. Utiliza as abordagens da pesquisa qualitativa e do método interpretativo para analisar os dados. Aponta os seguintes resultados: os sujeitos indicam que, na prática, a formação fica engessada, à medida que se desenvolve sob um viés tecnicista. Conclui que para uma formação mais eficiente, com a inclusão das TIC na prática docente, é necessário que ela seja integrada e sistematizada por todo o currículo do curso.

Palavras-chave: Licenciatura. Matemática. Formação de professores. TIC. Educação básica.

\begin{abstract}
This study is an excerpt from the master's research entitled "ICT in the initial training process of students in the Mathematics Degree course at UFMT". It is a member of the Group of Studies and Research in Mathematical Education (GRUEPEM) with funding from CAPES. It seeks to understand the contributions of the subjects of Technologies to the Teaching of Mathematics in the formative process of the students of the Mathematics degree course at the Federal University of Mato Grosso (UFMT), Campus Cuiabá. The investigations produced under this perspective have found that, in order to include them efficiently, it is necessary to creat them as a resource that enhances learning, and not just as a tool to speed up an activity. Therefore, in this work a theoretical approach is presented on the initial training of mathematics teachers, and how this training should be oriented towards the inclusion of technologies.
\end{abstract}


It uses the approaches of qualitative research and the interpretive method to analyze the data. Points out the following results: the subjects indicate that, in practice, training is in a cast, as it develops under a technicist bias. It concludes that for more efficient training, with the inclusion of ICT in later teaching practice, it is necessary that it be integrated and systematized throughout the course curriculum.

Keywords: Graduation. Mathematics. Teacher training. ICT. Basic education.

\section{Introdução}

A educação sofreu, ao longo dos anos, inúmeras transformações. Deste modo, a relação professor-aluno mudou, pois antigamente a escola era centrada no professor e, atualmente, a tendência é que este se torne mediador do processo educacional. Esse novo contexto social indica a necessidade de uma mudança na formação inicial dos professores, pois é nesse momento que os conhecimentos básicos para a docência são adquiridos.

Gatti (2013) defende uma formação inicial de professores que proporcione uma base teórica sólida não apenas centrada na racionalidade técnica. Uma formação inicial que, além de se preocupar com a compreensão de conteúdos teóricos e a melhor maneira de aplicá-los na prática, compreenda os vários outros âmbitos que rodeiam esse processo. A atividade docente não pode mais ser pautada no domínio de conteúdos e nas técnicas para transmiti-los.

No que se refere à formação inicial de professores de matemática, Polettini (1999), Blanco (2003) e D'Ambrosio (2008) indicam que uma formação inicial com qualidade não significa somente o conhecimento da Matemática enquanto ciência. Além disso, é necessário que se compreenda o conhecimento de como lecionar o conteúdo e do conhecimento do currículo, de forma integrada. A respeito dessa forma de construir o conhecimento da Matemática de uma forma integrada, as Tecnologias da Informação e Comunicação (TIC) podem ser bem exploradas quando planejadas de uma maneira que possam potencializar a aprendizagem.

Autores como Ponte (2000), Pretto (2002) e Alonso (2008) enfatizam a importância das ferramentas midiáticas e a nova maneira de se conceber a educação com a inclusão delas nos processos de ensino-aprendizagem. Para tanto, é necessário que os professores saibam como potencializar suas atividades com o acréscimo das TIC e seja abandonada a ideia de que utilizar os recursos signifique colocar apenas os alunos em contato com algum software, ligados à internet sem sistematização alguma.

Deste modo, o objetivo da pesquisa de mestrado desenvolvida foi compreender as contribuições das disciplinas de Tecnologias para o Ensino de Matemática no processo formativo dos acadêmicos do curso de licenciatura plena em Matemática da UFMT - Campus 
Cuiabá. Para este texto, em especial, apresentamos um recorte dos dados da pesquisa sobre as concepções dos alunos da Licenciatura em Matemática a respeito da sua formação inicial para as TIC. Sendo assim, o presente trabalho se constitui como um recorte da pesquisa de mestrado desenvolvida na UFMT/PPGE/IE. Acreditamos que as contribuições dos acadêmicos da Licenciatura em Matemática permitiram compreender como a formação para as TIC está sendo promovida no contexto da universidade, mais especificamente, na Licenciatura em Matemática.

Para uma melhor compreensão deste texto apresenta-se a seguinte organização em tópicos: a formação inicial de professores de matemática da Educação Básica; as TIC na formação inicial de professores; as TIC na formação inicial de professores de matemática; percurso metodológico; o contexto e sujeitos da pesquisa; instrumentos de coleta de dados; a análise dos dados; considerações sobre a pesquisa e as referências.

\section{A formação inicial de professores de matemática da educação básica}

A formação docente deve ser vista como um espaço de ampla discussão nos espaços escolares, pois se, por um lado, os alunos e professores se encontram em constante mudança de ideias e o perfil profissional pretendido evolui, por outro, os currículos dos cursos levam um tempo maior para se modernizar.

Para Blanco (2003, p. 53), o conhecimento matemático do professor é composto por dois pilares básicos: "o conhecimento do professor: conceituação, domínios e estrutura; e a aprendizagem do professor de matemática: conceituação e caracterização". Segundo esta autora, são esses os pilares básicos que possibilitam a construção de currículos, a partir da educação matemática. Para ela, o currículo da formação inicial de professores de matemática deve procurar sistematizar disciplinas interdisciplinares como meta para se atingir tais pilares básicos.

Ao colaborar na discussão a respeito da formação inicial de professores de matemática, Garnica (1996) sugere um eixo norteador de especificidades que deve ser observado em uma visão panorâmica dos currículos. Neste eixo, parafraseando o autor, destaca-se: a profissionalização da atividade docente e a do licenciando - estagiário; articulação entre escola e universidade; rompimento da dualidade específico-pedagógico que tem caracterizado os cursos de licenciatura; necessidade de existência de conselhos de cursos (um dos responsáveis por estabelecer um comprometimento das instituições com as questões pedagógicas) e projetos pedagógicos para a graduação (norteadores da formação); fortalecimento das pesquisas em 
educação e em educação matemática; implementação de projetos de pesquisa para licenciandos e professores em atuação; reavaliação de aspectos como evasão, retenção e expectativas; compromisso das instituições de ensino superior com relação ao ensino e a necessidade que a fase de análise de propostas seja ultrapassada pela viabilização de ações.

Deste modo, por meio de tais diretrizes gerais, os cursos encontram sugestões de como organizar seus currículos, respeitando seus limites regionais e, ainda, preservando sua autonomia. Neste ponto, ressalta-se a importância de os cursos terem liberdade para a elaboração de seu Projeto Político de Curso (PPC) devido a inúmeras diferenças regionais e o perfil pretendido do aluno egresso. Em relação aos conhecimentos que deverão constituir o currículo de um curso de formação inicial de professores, Blanco menciona que os seguintes aspectos devem, de algum modo, compor a estrutura deles:

o conhecimento de e sobre a matemática, considerando também as variáveis curriculares; o conhecimento de e sobre o processo de geração das noções matemáticas; o conhecimento sobre as interações em sala de aula, tanto entre professor-aluno como entre aluno-aluno em sua dupla dimensão: arquitetura relacional (rotinas instrucionais) e negociação de significados (contrato didático); o conhecimento sobre o processo instrutivo - formas de trabalhar em classe, o papel do professor - que exige, também, o conhecimento sobre as representações instrucionais e o conhecimento sobre as características da relação tarefa-atividade (BLANCO, 2003, p. 71).

Assim, uma formação inicial básica que aborde esses conceitos promoverá os subsídios para que o professor recente na profissão tenha bom embasamento teórico-metodológico no desenvolvimento de suas aulas. Esses requisitos promoverão o posterior desenvolvimento para a formação continuada, bem como a resolução de problemas em matemática e as conexões desta com o cotidiano dos alunos. Polettini (1999, p. 248) ao teorizar sobre a formação inicial de professores de matemática, enfatiza que

A imagem do professor mudou de uma figura passiva para a de uma figura
ativa, construindo perspectivas e escolhendo ações. O ensino deixou de ser
visto apenas como transmissão de conhecimento, trabalho conduzido
essencialmente de forma isolada. A nova visão é a de atividade não-rotineira,
conduzida de forma colaborativa.

Nesse sentido, é necessária a participação mais ativa dos alunos no seu próprio processo de formação, procurando priorizar uma formação que instigue a investigação e a pesquisa em sala de aula. Assim, Polettini (1999, p. 258) sugere um programa de formação de professores de matemática que busque 
1. Propiciar oportunidades para incentivo à reflexão sobre as experiências (matemáticas e não-matemáticas) passadas e presentes; 2. Buscar a discussão do conhecimento do conteúdo, do conhecimento de como lecionar o conteúdo e do conhecimento do currículo de forma integrada sempre que possível; 3. Incentivar trabalhos baseados não no isolamento, mas na colaboração entre os alunos e docentes; 4. Propiciar oportunidades de experiências com escolas de $1^{\circ}$ e $2^{\circ}$ graus e alunos o mais cedo possível; 5. Incentivar a discussão de uma visão de Educação Matemática, e não de Ensino de Matemática, que deva permear todo o trabalho.

Desta forma, o professor de matemática tem um papel bastante complexo e exigente e a sua formação inicial deve atender a estas especificidades formativas. Ele não deve ser o profissional que replica métodos. Existem inúmeras particularidades de sua profissão que exigem que ele mobilize saberes e competências de inúmeros domínios. Assim, a formação inicial de professores de matemática é um processo bastante intenso, no qual as instituições formadoras devem proporcionar experiências formativas que situem, de fato, o acadêmico para o exercício de sua posterior atividade docente.

\section{As TIC na formação inicial de professores}

Para uma escola que conduza seus alunos ao desenvolvimento da criticidade e autonomia, conforme discutido anteriormente, faz-se necessário que o professor saiba como capacitar seus alunos para este perfil. Dessa maneira, para que façam uso das TIC em sua atuação docente, é necessário que, no seu momento de formação inicial, o acadêmico tenha sido motivado a desenvolver uma prática coerente com as necessidades básicas para aprender Matemática. Logo, aqui nesta seção busca-se evidenciar o que os autores da área concebem como uma boa formação relativa às TIC na formação inicial.

De acordo com Pretto (2002, p. 124), “as escolas passam a ser equipadas com essas chamadas novas tecnologias, mas o sistema educacional, em última instância, permanece o mesmo: hierárquico, vertical, centralizado de forma exagerada". Ou seja, o autor indica que existem, sim, tecnologias nas escolas, mas isto promoveu pouca mudança nos processos de ensino-aprendizagem, pois as práticas docentes não se alteraram.

Inclusive, culpam o professor pelo fato de a escola ainda ser dessa maneira. Dizem que os professores não têm a capacitação necessária para o uso das TIC, ficando suas aulas fadadas ao fracasso. Pretto (2002) também indica que, quando a rotina da escola era restrita aos livros didáticos, a culpa também recaía nos professores que não compreendiam as propostas dos livros. O autor ainda menciona que, independentemente do material, a culpa do fracasso da educação está sempre no professor e explora que mudanças substanciais não poderão ser vistas, 
caso o centro das políticas públicas não esteja na escola e nos professores. Dessa forma, sobre a inclusão das TIC na escola, Pretto (2002, p. 130) discorre:

Não podemos, portanto, nos contentar com propostas de introdução dessas tecnologias na escola como se elas fossem, por si sós, as transformadoras de todo esse processo que está superado e que não dá conta das transformações do mundo contemporâneo: um planeta em movimento, não os conhecidos, tradicionais e harmônicos movimentos de rotação e translação, mas movimentos mais complexos, que fazem o mundo, também, mais complexo.

Assim, Pretto afirma que somente incluir não é suficiente, é necessário sistematizar as TIC, ressaltando a importância da capacitação adequada aos docentes, que, muitas vezes, não são formados para trabalhar com elas. A inclusão das TIC na escola, segundo Alonso (2008), colabora para uma crise de identidade dos professores. Quando tais tecnologias são incrementadas na educação, esta tende a ser ressignificada. Conforme a autora,

Se, com a aparição dos livros, houve questionamentos sobre a legitimidade do professor como "depositário" do saber, o caso das TIC traz à tona a discussão sobre o papel profissional dos professores nos processos de ensino/aprendizagem. Do ponto de vista pedagógico, o uso das TIC no contexto escolar e as significações sobre elas têm implicado transformações que relativizam a função do professor como transmissor de conhecimento, deslocando o centro da questão para o "protagonismo" dos alunos. O problema é que a escola, como instituição, está ainda marcada pela lógica da transmissão, fazendo colidir com a lógica das TIC e a lógica escolar (ALONSO, 2008, p. 754).

Nesse sentido, a formação de professores para trabalhar com as TIC deveria levar em conta o maior protagonismo, o que ainda não se verifica nos cursos de formação inicial de professores. O que mais se vê são cursos nos quais os licenciandos apenas assistem à aula tradicional, sem questioná-la. Essa prática provavelmente é repetida na atuação profissional deste formando. E quando a formação aponta para uma educação libertadora, a escola acaba impedindo o professor posteriormente, levando-o apenas a seguir o modelo que a escola já segue. Perante esse contexto, como uma maneira eficiente de incorporar, de fato, as TIC na sala de aula, Alonso (2008, p. 759) sugere:

O fato de valorar a mediação no processo do conhecer traz à cena outros conceitos. Assim, interação e interatividade aparecem como complementares ao ensinar/aprender. Junte-se a isso a ideia de que, se a informação circula, se está em fluxo constante de produção, transcendendo a escola, a situação para advogar a necessária transformação da profissão do docente igualmente se materializa. Mais que formação, exige-se a mobilização de conhecimentos que 
possam ser transformados em ação, compreendidos agora como competências.

A concepção da construção do conhecimento docente proposto pela autora indica a necessidade de os conhecimentos serem transformados em ação, reafirmando o compromisso de uma formação inicial que contemple competências. Portanto, a mediação pretendida ao trabalhar utilizando-se das TIC é estruturada de forma que os alunos interajam tanto com os colegas de classe, ressaltando aqui a importância da comunicação entre os pares, bem como na interatividade com os recursos disponíveis. Isto se deve ao fato de o conhecimento na contemporaneidade não ser mais estático, e, sim, se desenvolver por meio de uma rede de conhecimentos. Neste sentido, Ponte $(2000$, p. 87) indica que é necessário aos professores

encarar a formação que alia as possibilidades multifacetadas das TIC com as exigências de uma pedagogia centrada na atividade exploratória, na interação, na investigação e na realização de projetos. Ou seja, uma pedagogia centrada no desenvolvimento da pessoa em formação que não perde de vista a autenticidade dos objetivos formativos visados.

Porém, para este autor, importa resolver um paradoxo a respeito da aplicabilidade das TIC na educação:

Por um lado, promovendo as TIC, isto é, pondo de parte os receios e os preconceitos, integrá-las plenamente nas instituições educativas, criar condições de acesso facilitado, generalizar as oportunidades de formação. Por outro lado, criticando as TIC, isto é, mostrando que elas têm de ser enquadradas por uma pedagogia que valorize sobretudo a pessoa que aprende e os seus projetos, mantendo uma permanente preocupação crítica com a emancipação humana (PONTE, 2000, p. 88).

Ao ressaltar a importância de criticar as TIC, o autor se refere ao fato de não se tornar um dependente delas, mas para caminhar com vistas a uma educação emancipadora, educar para o pensar. As TIC não seguem um rumo estático e determinado, são voláteis. Cabe educar não para a submissão à tecnologia, mas para a liberdade.

Em um estudo desenvolvido por Karsenti (2009), o autor busca compreender melhor os efeitos das TIC na formação inicial de professores, suas atitudes diante dessa nova proposta de aprendizagem e suas práticas pedagógicas em sala de aula. A princípio, verificou-se que o incremento das TIC no exercício docente é bastante pequeno, decorrente do receio de se trabalhar com elas e, simplesmente, por não terem o devido conhecimento para isso. O referido autor constatou que o número de cursos que contam com o incremento das TIC na formação 
dos professores ainda é relativamente pequeno e, quando são apresentadas, as tecnologias são compreendidas como uma especialidade e não como um recurso de aplicação geral na didática e na pedagogia, o que indica a urgente necessidade de se abandonar essa ideia que impera na maioria dos cursos de formação de docentes.

Sendo assim, não tem efeito a utilização de tais recursos para tapar lacunas ou apenas inserindo-os no ensino sem sistematização alguma. $\mathrm{O}$ ensino deve ser revisto e adaptado às novas e inúmeras possibilidades que as tecnologias oferecem. A maneira pela qual essa inclusão é realizada varia de acordo com três concepções básicas, sendo elas, "1. o grau de alfabetização informática do docente; 2 . A representação que ele tem do papel que a informática escolar pode desempenhar no plano da aprendizagem; 3. As estratégias de intervenção pedagógica que o docente privilegia" (KARSENTI, 2009, p. 183).

Assim, observando as três concepções, conclui-se que, antes de aprender a trabalhar com as TIC e incorporá-las aos processos de ensino-aprendizagem, os professores têm que "vivê-las" inicialmente. Ou seja, ter na formação inicial o primeiro contato com elas. Depois desse primeiro contato e experimentação é que os ensinamentos vão sendo aperfeiçoados. Como afirma Karsenti (2009, p. 183),

As TIC não devem ser um objeto de aprendizagem; as TIC devem estar a serviço da pedagogia para que os futuros docentes sejam expostos a modelos eficazes de integração pedagógica das TIC [...] Para a reforma dos programas no primário e no secundário, as competências tecnopedagógicas são competências transversais que deveriam ser construídas pelos futuros docentes no conjunto de suas atividades de aprendizagem, e não em um único curso sobre as tecnologias.

Neste ponto, o autor chama a atenção para o fato de que disciplinas isoladas no currículo da formação inicial de professores não causam um impacto grandioso na formação deles. Para que elas sejam incluídas de maneira eficiente, deve-se priorizar sua utilização por todo o processo de formação, de uma maneira que transcenda as disciplinas e seja incluída em todas elas. Karsenti (2009) indica que existe uma falta de prática com as TIC nos cursos de formação inicial. Os acadêmicos aprendem a teoria, no laboratório, mas observa-se que a prática, nos momentos de estágio por exemplo, é bem limitada, e em determinados casos não existe. Essa ausência de contato com a prática relativa às TIC nos processos de ensino-aprendizagem pode ampliar a percepção de que as tecnologias somente podem ser utilizadas como uma função instrumental e não como material no contexto didático, pois entende-se que a experiência de observar profissionais experientes é de grande valor para o docente em formação. 
O Proinfo indica que a verdadeira inclusão das TIC em educação estaria atrelada a uma concepção construcionista. Nesta abordagem,

cabe ao professor promover a aprendizagem do aluno para que este possa construir o conhecimento dentro de um ambiente que o desafie e o motive para a exploração, a reflexão, a depuração de ideias e a descoberta. Antes de propor um plano, que deverá ser resultado de um trabalho cooperativo dos que estão envolvidos na aprendizagem, o professor precisa conhecer as potencialidades de seus alunos e suas experiências anteriores. Além disso, o professor cria situações para usar o microcomputador como instrumento de cultura, para propiciar o pensar-com e o pensar-sobre-o-pensar e identificar o nível de desenvolvimento do aluno e seu estilo de pensar (PROINFO, 2000, p. 77).

Neste sentido, com o intuito de atingir esse perfil profissional de docente, o ProInfo indica alguns requisitos que devem ser contemplados na formação inicial do professor para que este saiba como utilizar as TIC nos processos de ensino-aprendizagem. Portanto, é necessário que o professor em formação compreenda a melhor maneira de

aprender a aprender; ter autonomia para selecionar as informações pertinentes à sua ação; refletir sobre uma situação-problema e escolher a alternativa adequada de atuação para resolvê-la; refletir sobre os resultados obtidos e depurar seus procedimentos, reformulando suas ações; buscar compreender os conceitos envolvidos ou levantar e testar hipóteses (PROINFO, 2000, p. 110).

Deste modo, ao ensinar o professor a trabalhar com as tecnologias, é necessário que este tenha autonomia e por meio das vivências e reflexões compreenda a melhor forma de integrálas em sua prática docente, verificando os limites e as possibilidades para isso. Assim, essa formação pretendida não se restringe a apenas dimensões pedagógicas nem acumulação de teorias e práticas. Trata-se mais de uma formação que busque interagir tais dimensões, promovendo uma transformação na ação pedagógica, juntamente com as TIC.

Ponte e Serrazina complementam as competências desejadas na formação inicial para que um professor saiba como utilizar as TIC, sendo elas: "o conhecimento de implicações sociais e éticas das TIC; a capacidade de uso de software utilitário; a capacidade de uso e avaliação de software educativo e; a capacidade de uso de TIC em situações de ensinoaprendizagem" (PONTE; SERRAZINA, 1998, p. 12). Essas competências produzem mudanças na ação docente do professor, como ilustra o Quadro $n^{\circ} 1$ : 
Quadro 1 - Mudanças no papel do professor potenciadas pelas TIC

\begin{tabular}{|l|l|}
\hline \multicolumn{1}{|c|}{ VELHOS PAPÉIS } & \multicolumn{1}{c|}{ NOVOS PAPÉIS } \\
\hline Fornecer informação & Criar situações de aprendizagem \\
\hline Controlar & Desafiar, apoiar \\
\hline Uniformizar & Diversificar \\
\hline
\end{tabular}

Fonte: Ponte, Oliveira e Varandas (2003, p. 166).

Dessa maneira, para que o professor encare seu novo papel, é necessário, inicialmente, que ele tenha domínio e preparo para integrar as TIC em sua prática, conhecendo seus fundamentos e diversos usos, identificando o nível de desenvolvimento de seus alunos. Essas competências devem ser construídas, preferencialmente, no espaço de formação inicial desses docentes, não a entendendo como formação de especialistas em conteúdos específicos. $\mathrm{O}$ desenvolvimento delas compreende a ideia de um perfil de "aprender a aprender", inserindo as TIC como recursos apropriados para se repensar a própria prática, lembrando que se vive em uma sociedade em constante transformação.

\section{As TIC na formação inicial de professores de matemática}

Estudo desenvolvido por Barcelos, Behar e Passerino (2010) indicou que a inclusão de TIC no ensino-aprendizagem da matemática é relativamente pequena quando comparada com outras áreas do conhecimento. Este fato, segundo estes autores, pode estar relacionado com a ausência de tais conteúdos na formação inicial do licenciando. Como afirmam Richit e Maltempi (2010, p. 27),

[...] mudanças na estrutura curricular dos cursos de licenciatura tornam-se necessárias, de modo que o conhecimento específico seja valorizado, mas que não seja o fim único da formação inicial docente. Para tanto, entendemos que a construção do conhecimento matemático deve acontecer de forma contextualizada, ou seja, entrelaçada às demais atividades formativas do licenciando, usando recursos diversos, incluindo as tecnologias, e no âmbito de diferentes situações de sala de aula, isto é, de docência.

Assim, compreende-se a necessidade do conhecimento específico em matemática como essencial para a docência, mas não como suficiente. É necessário ir além, buscando contextualizar tal aprendizado, acreditando que as TIC podem ampliar e muito este potencial. Nesse viés, os referidos autores teorizam a respeito da importância de um paradigma construcionista na formação inicial de professores. Tal paradigma, ao contrário da concepção tradicional de ensino que prevalece no ensino da matemática, busca valorizar as ideias dos 
licenciandos. Com espaço para expô-las, os estudantes têm liberdade para o exercício da criatividade e, consequentemente, para a construção de um conhecimento mais sistematizado e complexo.

No paradigma construcionista de formação de professores, Richit e Maltempi (2010) indicam que deve existir o estímulo à autonomia e à investigação matemática. Por meio das TIC, torna-se mais palpável o ensino que estimule a autonomia e a investigação. Com o professor mudando sua postura para um perfil mediador dos processos de ensino-aprendizagem, as TIC se constituem como uma possibilidade aos alunos para percorrerem individualmente seu processo de ensino-aprendizagem e chegarem às mesmas soluções por caminhos distintos e específicos de cada sujeito. Na formação inicial, é importante a construção desses conceitos pelos professores, não como uma forma de proporcionar prazer imediato aos alunos, mas para promover o envolvimento pessoal deles e principalmente fazer sentido.

Neste caso, é necessário refletir a respeito do papel das tecnologias na formação e prática docente. É necessário que o professor saiba o conteúdo específico e pedagógico, mas não aprendidos isoladamente. $\mathrm{O}$ conhecimento da matemática se constrói de maneira contextualizada e, neste caso, podendo receber inúmeras contribuições das TIC.

De acordo com Richit e Maltempi (2010), as TIC têm a possibilidade de favorecer a autoestima e o trabalho colaborativo. A licenciatura em matemática se ocupa, na maior parte, em possibilitar o aprendizado do conteúdo específico e pedagógico e, muitas vezes, não acredita no potencial que as TIC podem proporcionar. Na pesquisa desenvolvida pelos referidos autores, os sujeitos responderam que o uso das TIC despertara neles a confiança em si, visto que desenvolveram as atividades com autonomia e os professores em formação ajudavam uns aos outros, trabalhando de maneira coletiva. As TIC representam uma parte bastante importante do conhecimento profissional dos professores, pois indicam ser recursos cada vez mais presentes na atuação dos docentes. Como destacam Ponte, Oliveira e Varandas (2003, p. 163), as TIC constituem, na prática de professores de matemática:

a) um meio educacional auxiliar para apoiar a aprendizagem dos alunos; b) um instrumento de produtividade pessoal, para preparar material para as aulas, para realizar tarefas administrativas e para procurar informações e materiais; c) um meio interativo para interagir e colaborar com outros professores e parceiros educacionais.

Desta forma, as TIC, além de serem utilizadas como recurso docente para a melhoria da prática pedagógica, auxiliam na otimização da atuação docente, proporcionando melhor forma 
de organização e comunicação com os pares e desenvolvimento de novas ideias. Para colaborar na discussão, como forma de incrementar as TIC no processo de formação inicial, Aguiar, Sette e Sette (2001, p. 38) acrescentam:

\begin{abstract}
Ao se tratar de informática na formação de professores, entende-se que o suporte teórico constitui a base imprescindível ao domínio pedagógico das ferramentas computacionais. Por isso, a recomendação é que os cursos de licenciatura conjuguem, de forma integrada na estruturação curricular, conteúdos oriundos das diversas ciências e outros voltados para a instrumentalização/profissionalização. Assim, o uso do computador se dará nos conteúdos e nas atividades desenvolvidas ao longo do curso, na construção do conhecimento, procurando evitar novas dicotomias que muitas vezes venham concorrer para a fragmentação da prática pedagógica.
\end{abstract}

Portanto, a aprendizagem para as TIC na formação de professores necessita ser interdisciplinar, como forma de minimizar a fragmentação dos currículos, visando uma maior integração que faça sentido aos licenciandos. Assim, percebe-se que as TIC podem ser incluídas na escola como potencializadoras da aprendizagem, mas que sozinhas ainda não são suficientes. Cabe ao professor em formação compreender os meios mais adequados para incrementá-las. Essa formação ainda não está completa e sistematizada, pois, como se pode perceber, a sociedade ainda é uma espécie de "cobaia" nessa inclusão recente. O que não se pode é simplesmente ignorá-las, pois esse perfil de professor não tem mais espaço no atual contexto do mundo globalizado.

\title{
Percurso metodológico
}

A pesquisa desenvolve-se sob o viés da abordagem qualitativa, segundo Bogdan e Biklen (1994), e caracteriza como um estudo de caso, em que buscou-se compreender um fenômeno singular, valorado em si mesmo, de acordo com Yin (2010).

Sendo assim, de acordo com as características enunciadas, a escolha de caso é pertinente quando se busca entender um determinado fenômeno social em profundidade, porém com o entendimento das condições contextuais nas quais está inserido, no caso, as TIC na formação inicial de professores, no contexto do curso de licenciatura em matemática da UFMT, Campus de Cuiabá. 


\section{$O$ contexto e sujeitos da pesquisa}

A pesquisa se desenvolveu com alunos regularmente matriculados no curso de Licenciatura Plena em Matemática da Universidade Federal de Mato Grosso, Campus de Cuiabá. Para além deste critério, o sujeito deveria ter cursado e sido aprovado nas disciplinas denominadas Tecnologias para o Ensino da Matemática I e II.

De acordo com as informações disponibilizadas pela coordenação do curso de Licenciatura em Matemática, observou-se que haviam sido matriculados na disciplina um total de 9 alunos, porém apenas quatro deles obtiveram êxito e foram aprovados. Os quatro alunos foram, então, convidados a participar da pesquisa e foram identificados por nomes fictícios, denominados: João, Ana, José e Maria. O quadro $n^{\circ} 2$ apresenta a caracterização do perfil dos sujeitos.

Quadro 2 - Perfil dos sujeitos entrevistados

\begin{tabular}{|c|c|c|c|c|}
\hline NOME & IDADE & INÍCIO DO CURSO & FORMAÇãO & TÉRMINO DO EM \\
\hline João & 30 anos & $2015 / 2$ & $\begin{array}{c}\text { Técnico de Recursos } \\
\text { Humanos }\end{array}$ & Supletivo -2008 \\
\hline Ana & 20 anos & $2016 / 1$ & $1^{\text {a }}$ graduação & 2015 \\
\hline José & 21 anos & $2016 / 1$ & $1^{\text {a }}$ graduação & 2015 \\
\hline Maria & 23 anos & $2016 / 2$ & $1^{\text {a } \text { graduação }}$ & 2013 \\
\hline
\end{tabular}

Fonte: Elaborado pelos pesquisadores.

Por meio do perfil traçado, é possível perceber que três deles são da mesma faixa etária e cursam a primeira graduação. João é o sujeito que tem a maior idade do grupo, além de já ter cursado uma primeira graduação e, atualmente, estar em sua segunda formação.

\section{Instrumentos de coleta de dados}

Os instrumentos foram análise de documentos (Projeto Político Pedagógico de curso (PPP) da Licenciatura em Matemática da Universidade Federal de Mato Grosso, Campus Cuiabá) e a entrevista semiestruturada. Estes instrumentos permitem compor a triangulação de dados para a compreensão do fenômeno de estudo. Essa entrevista buscou compreender o que dizem os alunos sobre as TIC em sua formação. Assim, será possível triangular as seguintes informações: o que o PPP aborda e como essa orientação reflete na formação dos alunos na concepção deles. As entrevistas aconteceram no período de maio-junho de 2019. Período definido por ser o início do primeiro semestre letivo do referido ano. 


\section{A análise dos dados}

\section{Concepções sobre a formação inicial do professor de matemática}

Neste eixo de análise, buscou-se ouvir dos sujeitos entrevistados na pesquisa algumas das suas considerações sobre a sua formação para a docência em matemática. Esta análise é importante à medida que a partir delas se tem condições para compreender as perspectivas teóricas que o futuro professor irá adotar na sua ação docente.

Assim, questionam-se os participantes da pesquisa sobre qual a sua compreensão de matemática, ou seja, em um sentido mais amplo, o que significa a matemática. Para João, a matemática é vista em várias situações no dia a dia:

Então, a matemática é bem abrangente. Mas assim, naturalmente eu a vejo como uma
ferramenta. Implicitamente ou explicitamente, ela está em atos simples. Eu vejo que
matemática é uma receita de bolo, o trajeto de um ônibus, o caminho de casa, é algo
que está ligado ao dia a dia em todos os sentidos. Todo mundo pergunta sem perceber
que horas são, mas o que essa hora quer dizer, o que esse intervalo de tempo significa.
Por que que eu preciso saber que horas são? Eu acho que a matemática tá dentro de
tudo assim. Eu não consigo achar uma palavra que define tudo isso (João, 2019).

No excerto, João compreende que a matemática está atrelada a situações do cotidiano. Embora ele afirme que a matemática é vista como uma ferramenta, o restante de sua fala não concorda com isso.

Em sua fala, cita inúmeros exemplos de como relacioná-la ao cotidiano, nas mais diversas situações, o que indica, na compreensão deste sujeito, que a matemática é um espaço de inúmeras construções que podem ser relacionadas ao cotidiano.

Quando a formação é orientada para a construção de conteúdos matemáticos, além dos muros da universidade, concepções como as de João tornam-se mais comuns. Sendo assim, ao pensar a inclusão das TIC dentro desse paradigma, concorda-se com o que teorizam Kenski (2007) e Alonso (2008). Segundo essas autoras, para existir a verdadeira inclusão das TIC na sala de aula, é necessário compreendê-las como recursos com potenciais em evidência, e não como uma ferramenta que desenvolve uma única ação. Na concepção de Ana:

Para mim, matemática é aquela coisa de sempre tipo, ciência exata. Para mim enquanto profissão, eu sempre me identifiquei com matemática e eu penso assim: é uma ciência exata onde a gente estuda na verdade comportamento. Eu compreendo que a matemática estuda na verdade o comportamento dos números (Ana, 2019).

Para ela, a matemática é vista como aquela ciência dos padrões, conforme descrita por Devlin (2005), que a vê como a ciência da ordem, padrões, estruturas e suas relações lógicas. 
Para este autor, a matemática atuaria como se fossem óculos que permitem ver e compreender os padrões do mundo.

Nesse sentido, ao estudar o comportamento dos números, fica implícito que eles podem surgir nos mais diferentes contextos, nas mais diversas situações. Sendo assim, mesmo que Ana admita a matemática como uma ciência exata, que remete a uma ideia de que o conhecimento está posto e acabado, ela fala do comportamento. Isso indica que inúmeras podem ser as aplicações da matemática, e que, portanto, estudá-la significa compreender esses padrões. Para José, a Matemática está relacionada com a resolução de problemas:

A matemática para mim é conta. Entender os números, trabalhar com os números, saber resolver problemas de diversas áreas usando a matemática (José, 2019).

Para este sujeito, a matemática está relacionada a contas, ao entendimento dos números e à forma de trabalhar com eles. Ao enfatizar que a matemática auxilia na resolução de problemas das mais diversas áreas, José indica que ela é um espaço de bastante criatividade, por existirem inúmeras áreas. Essa visão pode indicar que ele compreende essa área do conhecimento como uma criação humana, onde o homem faz as relações que necessita de acordo com os problemas que surgem. No relato de Maria, observa-se o seguinte:

Matemática para mim é uma filosofia. Quando você tenta estabelecer uma relação de
uma ideia, e você consegue construir com essa ideia outras ideias, você está
exercitando a matemática. É uma filosofia que permite que o homem consiga
construir coisas além do que ele consegue ver. Ele consegue padronizar algumas
coisas que ele já tem alguma ideia sobre isso e depois, ele consegue criar a partir
dessa ideia (Maria, 2019).

Maria apresenta uma visão construcionista da matemática. Para ela, por meio de questões que a matemática já construiu, é possível ao homem pensar, exercitar e construir novas ideias. Sua concepção é importante quando se pensa que as TIC devem ser incluídas em ambientes construcionistas. Tais ambientes atuam no desenvolvimento da criticidade do aluno.

Nesses ambientes, compreende-se que a simples execução de algoritmos não tem grande impacto na aprendizagem. Neste sentido, salienta-se a importância da resolução de problemas. Como docente da Educação Básica, pode-se perceber que, quando os alunos têm o devido tempo para resolver problemas, pensar e formular hipóteses, eles absorvem com melhor entendimento o conteúdo, ao contrário de quando expostos à repetição de métodos.

Por meio das concepções expostas neste eixo, percebe-se que os sujeitos da pesquisa entendem a matemática como uma construção humana, atrelada ao cotidiano do aluno, rodeada de processos e não como uma ciência pronta e acabada. 


\section{Concepções sobre as TIC no ensino de matemática durante a formação inicial}

Na compreensão do PPP do curso analisado, além de incorporar novas tecnologias no processo de ensino-aprendizagem, apenas incluí-las não é o suficiente: é necessário que elas façam sentido para o aluno, adequando-se à sua rotina, pois, como afirmam Richit e Maltempi (2010), o conhecimento matemático deve ser contextualizado.

A respeito dos conteúdos e conhecimentos necessários à formação, o documento indica que, para a metodologia do ensino de matemática, "o uso de recursos didáticos e das novas tecnologias devem compor a formação" (UFMT, 2009, p. 10). Assim, buscou-se analisar como as disciplinas relacionadas às TIC estão constituídas no ementário, conforme ilustra o quadro adiante:

Quadro 3 - Disciplinas do ementário que envolvem as TIC diretamente

\begin{tabular}{|l|c|l|}
\hline DISCIPLINA & CARGA HORÁRIA & EMENTA \\
\hline $\begin{array}{l}\text { Tecnologias para o Ensino de } \\
\text { Matemática I }\end{array}$ & $60 \mathrm{~h}$ & $\begin{array}{l}\text { Tecnologias para o ensino de matemática: } \\
\text { calculadoras, mídias e sites; análise e } \\
\text { utilização. Softwares educacionais para } \\
\text { apoio ao ensino de geometria e álgebra na } \\
\text { Educação Básica. }\end{array}$ \\
\hline $\begin{array}{l}\text { Tecnologias para o Ensino de } \\
\text { Matemática II }\end{array}$ & $75 \mathrm{~h}$ & $\begin{array}{l}\text { Tecnologias da Informação e } \\
\text { Comunicação (TIC) e o ensino de } \\
\text { Matemática. Educação Matemática e } \\
\text { ambientes virtuais de aprendizagem e } \\
\text { tutoria. Avaliação e produção de materiais } \\
\text { didáticos para o ensino de matemática } \\
\text { com o uso das TIC. }\end{array}$ \\
\hline
\end{tabular}

Fonte: Elaborado pelos autores com base no PPP da Licenciatura em Matemática (UFMT, 2009).

Como verificou-se no quadro anterior, disciplinas referentes às TIC durante o processo formativo existem na grade curricular do curso. Sendo assim, em seguida buscou-se compreender as concepções dos alunos da licenciatura em Matemática a respeito de como ocorre e as nuances que permeiam essa inclusão.

Inicialmente, busca-se compreender se os sujeitos acreditam ser possível desenvolver o pensamento crítico e a reflexão ao empregar as TIC como potencializadora do processo de ensino-aprendizagem. José assim indica:

Eu acho que sim, mas acredito que desenvolve mais quando é um conteúdo avançado. Por exemplo, usando um software lá no computador, ao ensinar soma de frações, $o$ máximo que ele vaifazer é desenhar figuras geométricas que representa isso e aquilo, e vai fazer comparações, o que na minha compreensão, não desenvolve muito a criticidade. Agora, na faculdade, você desenha a função no software, você pode explorar o método da secante, o método de Newton, que ajuda a ter uma reflexão em pontos mais específicos (José, 2019). 
Na fala de José, as TIC, quando empregadas em situações simples, não atuam no desenvolvimento da criticidade, pois, segundo ele, a forma pela qual determinado programa aborda o ensino não contribui de maneira relevante. Essa concepção do sujeito pode estar relacionada ao fato de ele não ter desenvolvido as competências necessárias para utilizar as TIC no ensino básico. O sujeito indica que ao utilizar as TIC em conteúdos mais avançados é que se desenvolve a criticidade mais intensamente, o que pode indicar que foi o conteúdo ao qual mais se deu ênfase em sua formação, em detrimento de conteúdos da Educação Básica.

A respeito da motivação para aprender a utilizar as TIC no ensino da matemática, no contexto da universidade, João argumenta:

Parece que só é dado por que precisa ser dado. Incentivo para isso, quase nenhum.
Os professores mais novos que estudaram essa área aqui, até tentam. Eles mexem sim
com isso, gosta de falar disso, mas é uma coisa deles, diferente do resto do coletivo.
Na minha opinião, TIC é algo novo. Então você imagina uma pessoa de 60 anos: não
vai ser fácil isso. É difícil lidar com aquilo. Eu mesmo com 30 anos, tenho muitas
dificuldades (João, 2019).

Neste ponto, João indica que a fragmentação de conteúdos relacionados às TIC na universidade se deve, dentre outros motivos, a determinados perfis de professores que não as incluem em suas aulas. Nas considerações deste sujeito, os esforços para incentivar os alunos a utilizarem as TIC em sua prática docente posterior ocorrem somente nas disciplinas denominadas Tecnologias para o Ensino da Matemática I e II. Raramente, nas outras disciplinas do currículo esse incentivo ocorre.

Essa constatação é importante, pois, restringindo as TIC a duas disciplinas específicas, os acadêmicos acabam não percebendo o potencial delas caso fossem utilizadas de maneira transversal, conforme indicam Aguiar, Sette e Sette (2001).

Em seguida, buscou-se compreender nas concepções dos sujeitos se existe supervalorização de um ou outro conteúdo na ementa das duas disciplinas relacionadas às TIC. Ana indica:

Em Tecnologias para o Ensino da Matemática II, a gente viu ensino a distância. A gente lia um artigo sobre a educação à distância, como sendo a primeira atividade. A ideia geral é intermediar aquilo através das tecnologias digitais. Aprendi a utilizar o LaTeX. Fiz slides no LaTeX. Daí teve casos em que usamos muito GeoGebra, tudo para pensar uma forma de colocar aquilo na internet, para que um aluno que esteja estudando de longe possa compreender. Eu achei bem legal porque tinha um conteúdo inserido (Ana, 2019).

Nas experiências de Ana na disciplina, verifica-se que houve a utilização de softwares como o LaTeX e o GeoGebra. Porém, na concepção dela, esse uso foi para confeccionar material para o Ensino a distância. Neste ponto, acredita-se que o conhecimento desses 
conceitos seja relevante, visto que já são inúmeras as iniciativas de ensino por meio dessa modalidade. Porém, Kenski (2007) destaca que um dos maiores problemas das TIC na formação reside na não adequação da tecnologia ao conteúdo que vai ser ensinado nas escolas.

É louvável a iniciativa de promover conhecimentos dessa natureza, mas o foco principal, isto é, a educação básica na modalidade regular, não deve ser inferiorizado. No relato de José:

\begin{abstract}
[...] Algo que eu aprendi realmente, que eu sei bem é o LaTeX, que foi uma coisa que me ajudou muito. Porém, este software está relacionado com formatação de textos matemáticos, não é uma coisa específica do ensino da matemática. O LaTeX é mais um editor de textos. Aprendi a utilizar o GeoGebra também, mas muito pouco. Nele, eu aprendi a digitar função, e o software mostrar como é o gráfico. Aprendi também neste software a fazer círculo, marcar pontos, marcar valores máximos e mínimos de funções, aprendi a construir matrizes. Mas isso também é só digitação, eu digito lá e o software que faz todo o trabalho. Para ensinar matemática mesmo, não teve nenhum software (José, 2019).
\end{abstract}

As contribuições de José indicam que ele aprendeu a utilizar bem o software de digitação de textos matemáticos. Porém, o sujeito indica que do ponto de vista do ensino da matemática a ferramenta não é tão significativa assim. Em resumo, o que de fato trabalhou com questões do ensino da matemática foi o software GeoGebra. Percebe-se que inúmeras foram as aplicabilidades do software. Entretanto, na concepção do sujeito, essas contribuições ainda não são significativas do ponto de vista de aplicá-las no ensino.

De maneira geral, neste eixo de análise, foi possível perceber que, de fato, os acadêmicos da graduação compreendem o amplo potencial que as TIC detêm quando incluídas pedagogicamente na educação. No entanto, percebe-se nos relatos que falta motivação para aprender com elas por parte de seus professores, a prática pedagógica ainda é bastante limitada.

No contexto que os sujeitos entrevistados estão inseridos, a disciplina se caracterizou como a compreensão de artifícios que possam facilitar a atuação dos professores, como a digitação de textos matemáticos ou uma inclusão bastante sutil, sem as devidas sistematizações que a tecnologia exige. Um aspecto muito preconizado durante a formação é o uso da tecnologia para compreender processos da educação superior, que, segundo os sujeitos, não tem aplicabilidade direta na Educação Básica.

\title{
Concepções dos sujeitos a respeito do uso das TIC como recursos nos processos de ensino- aprendizagem
}

Após compreender as concepções dos sujeitos a respeito das TIC na sua formação inicial, interessa-nos saber se eles se sentem seguros em planejar suas aulas com a inclusão das tecnologias. Sendo assim, segundo o relato de João: 
Eu tenho que me preparar mais. Foi dado a base, agora se quiser continuar, é como se fosse assim: Ah, eu achei interessante, agora vou atrás. Não é algo que já vem pronto (João, 2019).

Para o sujeito, existe um percurso para que essas aulas sejam planejadas. Ele compreende o ponto de partida e é detentor de recursos que podem lhe auxiliar na construção deste trajeto. Por outro lado, mesmo dizendo que não se sente preparado, ele não demonstra receio em preparar uma aula assim. Para ele, é necessário bastante planejamento, mas, de fato, é possível, pois compreendeu os conceitos fundamentais para se preparar aulas dessa natureza.

Conforme indicam Richit e Maltempi (2010), é necessário que os professores aprendam a explorar as mídias digitais de forma crítica, investigativa e autônoma não só na formação inicial. Esse processo se inicia na primeira formação, mas deve prosseguir por toda a carreira profissional do professor, indicando que João, mesmo ainda não tendo plena certeza de como fazer isso, compreende os caminhos para que possa, por meio de seu próprio percurso, incluir as TIC. Na concepção de Ana:

Eu não tinha noção nenhuma de LaTeX, então eu aprendi isso. O que teve muito foi
$o$ LaTeX. A gente também fez atividades de geometria dinâmica. Mas a gente não
aprendeu coisas do ensino básico. Fizemos umas atividades de geometria dinâmica
no GeoGebra para explicar por exemplo, o teorema do valor intermediário. Mas para
o ensino básico, não aprendemos nada. Aprendemos também a calcular áreas de
figuras planas no GeoGebra. A Tecnologia para o Ensino da Matemática II foi
basicamente conteúdo de graduação somente (Ana, 2019).

Uma frustração indicada por Ana decorre da inexistência, em sua concepção, de metodologias a serem aplicadas na Educação Básica. Ela indica que aprendeu bem como explicar conteúdos da matemática do ensino superior por meio da tecnologia, mas, quando se trata da matemática do ensino básico, esses conteúdos não foram amplos, ficando restritos a situações isoladas.

Nas concepções de Ana, que cursou as disciplinas de Tecnologias no ano de 2019, percebe-se uma intensa valorização do software LaTeX durante a disciplina. Esse software é um sistema de edição de documentos e sua supervalorização indica um ponto a se questionar. O uso dele ocupa ampla carga horária da disciplina e contribui mais intensamente na edição de textos matemáticos, e não muito na construção de conhecimento por meio da tecnologia.

Nesse sentido, segundo Richit e Maltempi (2010), desde a implementação de computadores na escola nos anos 80 e 90, seu uso pedagógico se resumia a atividades de edição e formatação de textos, com o intuito de familiarizar o aluno com a ferramenta, e não a utilizála como recurso. O que impressiona é verificar no relato de Ana que, após percorridos 30 anos da inclusão de computadores na escola, a prática ainda se repete. 
Maria entende que o conhecimento para a inclusão das TIC não cessa, conforme o relato:

\begin{abstract}
Por mais que a gente não tenha estudado tanto, eu penso que esse tipo de conhecimento não se cessa, você teria que saber onde buscar também. Então não me sinto segura, mas eu sei que certas coisas, eu posso procurar. É como se diz: a necessidade faz a ocasião. Talvez futuramente, eu poderia melhorar alguma coisa, mais seguro ou não, as duas disciplinas fornecem a base para que eu saiba onde procurar, o que procurar e como procurar" (Maria, 2019).
\end{abstract}

Maria reforça o que os outros sujeitos disseram: o conteúdo para o trabalho com as TIC no processo de formação inicial é um tanto quanto limitado, porém entendem que é normal que seja assim, visto que o professor é o principal agente de sua própria formação. Embora a literatura da área concorde com isso, é necessário que algumas práticas sejam alteradas por parte da coordenação de curso. Não faz mais sentido uma formação que priorize assuntos como a digitação de textos em determinados aplicativos, daí a importância da revisão dessas concepções.

A formação inicial, como o próprio nome já diz, é apenas o princípio do preparo do professor. Nela são construídos os pilares básicos para que, posteriormente, os professores possam seguir seus estudos. Isto também se aplica nos conteúdos formativos referentes às TIC nos processos de ensino-aprendizagem. As tecnologias são algo que se modifica constantemente. Inúmeros novos softwares surgem a cada dia, ao contrário da atualização dos currículos dos cursos de formação de professores, que levam um tempo maior para atualizarem suas ementas de disciplinas.

Desse modo, tendo em vista que a formação inicial para a inclusão da Tecnologia não dá conta de uma sistematização completa e acabada, buscou-se compreender o que os sujeitos aprenderam de significativo para a sua formação nas disciplinas que formam para as Tecnologias e que podem ser incluídas na Educação Básica. A respeito da temática, Maria relata o seguinte:

Aprendi principalmente ensinar geometrias, que é a parte mais visual e pouca coisa de função. Eu faria isso utilizando softwares como GeoGebra e o Wolfran Alpha (Maria, 2019).

Nas experiências de Maria com as disciplinas analisadas, ela indica que apesar de ter aprendido poucos conteúdos, aprendeu a ensinar geometria utilizando softwares como o GeoGebra e o Wolfran Alpha. No relato dela, percebe-se que aquilo de fato impactou a formação dela e pode ser aplicado na Educação Básica. Como já se discutiu em outros momentos da pesquisa, a formação para as Tecnologias está muito atrelada apenas à construção 
de conceitos do ponto de vista da matemática do Ensino Superior e pouco relacionada à Educação Básica.

Como afirmam Ponte, Oliveira e Varandas (2003), as TIC devem ser um meio auxiliar para apoiar a aprendizagem dos alunos. Porém, se a formação do professor é limitada à construção de poucos conceitos, essa aprendizagem torna-se engessada. José, ao discorrer sobre o assunto, informa:

Aprendi também a usar a calculadora de modo a impulsionar o processo de ensinoaprendizagem. Isso foi incrível, porque me ajudou a ver com outros olhares essa ferramenta (José, 2019).

Nas concepções de José, é possível verificar que uma tecnologia que se subentende que os alunos já conheçam foi ressignificada. Ele aprendeu a trabalhar com as inúmeras possibilidades que a calculadora tem e que podem ser exploradas na Educação Básica. Interessante verificar que, quando se analisa do ponto de vista histórico, a calculadora e o celular eram recriminados pelas escolas, inclusive excluídos do processo. No entanto, com o novo papel das tecnologias no ensino, como afirmam Ponte, Oliveira e Varandas (2003), esses recursos têm amplo potencial a serem descobertos, vistos com inúmeras possibilidades e não mais como um empecilho à aprendizagem.

Não incluir as TIC nos processos de ensino-aprendizagem significa o mesmo que ir de modo contrário ao movimento atual de educação no contexto escolar, pois elas já são quase parte dos estudantes. Sendo assim, utilizá-las na educação significa ampliar as formas de se construir conhecimento e conduzir o aluno à verdadeira aprendizagem significativa do conhecimento escolar. A tecnologia contribui de forma eficaz para o processo ensino e aprendizagem na educação escolar brasileira. Logo, com o auxílio da tecnologia, é possível desmistificar a ideia de que aprender matemática é difícil, concepção essa que muitos alunos e professores da Educação Básica ainda não abandonaram.

\section{Considerações sobre a pesquisa}

Os dados produzidos pela pesquisa apontaram que os alunos notam a existência de inúmeras possibilidades de inclusão das tecnologias nos processos de ensino-aprendizagem, porém quando vão descrever essas possibilidades, verifica-se que eles não têm a ideia de como fazer isso. Percebe-se, neste fato, um indicativo de uma formação frágil para as tecnologias. Os 
sujeitos indicam, ainda, que, durante as disciplinas, a formação estava restrita a entender a tecnologia como uma ferramenta para agilizar um processo e não como um recurso.

No relato deles existe intensa valorização de softwares como o LaTeX, por exemplo. Este software restringe-se, quase sempre, à digitação de textos matemáticos. Sendo assim, o uso para esta finalidade, do ponto de vista dos teóricos que sustentam as discussões, não entende o software como um recurso que potencializa a aprendizagem, mas como um instrumento sem grandes contribuições.

Os dados da pesquisa também indicaram que os acadêmicos acreditam que para trabalhar com as TIC só o computador é o recurso adequado. As outras tecnologias acabam sendo esquecidas. Isso indica que, na formação inicial, não é dada ênfase às inúmeras potencialidades que as TIC ofertam, a formação é restrita ao uso do computador. Esse paradigma de formação é insuficiente, visto que muitos dos laboratórios da educação básica são inexistentes, mas muitos dos alunos têm aparelhos do tipo smartphones - com a possibilidade de trabalho em grupo para contemplar aqueles que não têm. Então, a formação faria mais sentido se fossem desenvolvidas as possibilidades de uso desse recurso nos processos de ensinoaprendizagem, por fazer parte da realidade dos alunos.

Assim, nesta pesquisa, foi possível compreender como o curso de Licenciatura em Matemática da UFMT, Campus Cuiabá, proporciona a formação para as TIC ao aluno do curso. Conclui-se que essa formação existe, porém ainda precisa ser melhorada. Os sujeitos da pesquisa indicaram que a formação para as TIC no curso, na maioria dos casos, serve para compreender processos da Educação Superior ou simplesmente utilizar as tecnologias como uma ferramenta, e não um recurso didático pedagógico que seja significativo para o ensino e a aprendizagem da matemática na Educação Básica.

\section{Referências}

ALONSO, Kátia Morosov. Tecnologias da Informação e Comunicação e Formação de Professores: Sobre Rede e Escolas. Revista Educação e Sociedade. Campinas, v. 29, n. 104 Especial, p. 747-768, out. 2008.

AGUIAR, Márcia Angela; SETTE, José Sergio Antunes; SETTE, Sonia Schechtman. Formação de Professores e Informática na Educação: um caminho para a mudança. Brasília: PROINFO/MEC, 2001.

BARCELOS, Gilmara Teixeira; BEHAR, Patrícia Alejandra; PASSERINO, Liliana. Análise dos Impactos da Integração de Tecnologias na Formação Inicial de Professores de Matemática 
sobre a prática docente: um estudo de caso. XVI Workshop Sobre Informática na Escola XXX Congresso da Sociedade Brasileira de Computação. Anais..., Belo Horizonte, 2010.

BLANCO, Maria Mercedes García. A formação inicial de professores de matemática: fundamentos para a definição de um curriculum. In: FIORENTINI, Dario (Org.). Formação de professores de matemática: explorando novos caminhos com outros olhares. Campinas, SP: Mercado de Letras, 2003. p. 51-86.

BOGDAN, Robert; BIKLEN, Sari. Investigação qualitativa em educação: uma introdução à teoria e aos métodos. Porto: Porto Editora, 1994.

DEVLIN, Keith. O gene da Matemática. Tradução de Sérgio Moraes Rego. 2. ed. Rio de Janeiro: Record, 2005.

D’AMBROSIO, Ubiratan. Educação matemática: da teoria à prática. Campinas, SP: Papirus, 2008 .

GARNICA, Antonio Vicente Marafioti. Fascínio da técnica, declínio da crítica: um estudo sobre a prova rigorosa na formação do professor de matemática. Revista Zetetiké. Campinas, v. 4, n. 5, p. 7-28 jan.-jun., 1996.

GATTI, Bernadete Angelina. A formação inicial de professores para a Educação Básica: as licenciaturas. Revista USP. São Paulo, n. 100, p. 33-46, dez. 2013.

KARSENTI, Thierry. Impacto das TIC (Tecnologias de Informação e Comunicação) sobre a atitude, a motivação e a mudança nas práticas pedagógicas dos futuros professores. In: TARDIF, Maurice; LESSARD, Claude. O ofício de professor: história, perspectivas e desafios internacionais. Petrópolis RJ: Vozes, 2009. p. 181-199.

KENSKI, Vani Moreira. Educação e tecnologias: o novo ritmo da informação. Campinas, SP: Papirus, 2007.

POLETTINI, Altair de Fátima Furigo. Análise das experiências vividas determinando o desenvolvimento profissional do professor de matemática. In: BICUDO, M. A. V. (Org.).

Pesquisa em Educação Matemática: concepções e perspectivas. São Paulo: Editora UNESP, 1999. p. 247-261.

PONTE, João Pedro da. Tecnologias de informação e comunicação na formação de professores: que desafios? Revista Iberoamericana de Educación. Madrid, n. 24, p. 63-90, sep./dec. 2000.

; SERRAZINA, Lurdes. As novas tecnologias na formação inicial de professores. Lisboa: DAPP do ME, 1998.

; OLIVEIRA, Hélia; VARANDAS, José Manuel. O contributo das tecnologias da informação e da comunicação para o desenvolvimento do conhecimento e da identidade 
profissional. In: FIORENTINI, Dario (Org.). Formação de professores de matemática: explorando novos caminhos com outros olhares. Campinas, SP: Mercado de Letras, 2003. p. 159-192.

PRETTO, Nelson De Luca. Formação de professores exige rede! Revista Brasileira de Educação. Salvador - BA, n. 20, p. 121-156, mai./jun./jul./ago., 2002.

PROINFO. Informática e formação de professores: Coleção Informática para a mudança na educação. Organizadora Maria Elizabeth de Almeida. Brasília: Secretaria de Educação a Distância - SEED: Ministério da Educação, v. 13, 2000.

RICHIT, Adriana; MALTEMPI, Marcus Vinicius. Desafios e Possibilidades do Trabalho com Projetos e com tecnologias na Licenciatura em Matemática. Revista ZETETIKÉ. Unicamp v. 18, n. 33, jan./jun. 2010.

UFMT. Projeto Político Pedagógico de Licenciatura Plena em Matemática. Cuiabá: UFMT, 2009.

YIN, Robert. Estudo de caso: planejamento e métodos. Porto Alegre: Bookman, 2010. 